\title{
Osteoprotegerin: A Promising Biomarker in the Metabolic Syndrome - New Perspectives
}

\section{Carmen Perez de Ciriza Villacampa*}

Laboratorio Pasteur, Clinical Biochemistry Department, Andorra la Vella, Andorra

*Corresponding author: Carmen Perez de Ciriza Villacampa, Laboratorio Pasteur, Clinical Biochemistry Department, Andorra la Vella, Andorra, Tel: +376805905; Email: cperezdecir@gmail.com

Rec date: Jun 20, 2016; Acc date: Sep 12, 2016; Pub date: Sep 15, 2016

Copyright: ( 2016 Villacampa CPC. This is an open-access article distributed under the terms of the Creative Commons Attribution License, which permits unrestricted use, distribution, and reproduction in any medium, provided the original author and source are credited.

\begin{abstract}
The metabolic syndrome (MS) is a cluster of cardio-metabolic alterations that has been known to increase the cardiovascular risk in these patients. The pathophysiological mechanisms underlying this observation remain unclear. In this context, osteoprotegerin (OPG) has emerged as a possible mechanism. The implication of OPG in cardiovascular disease and cardiovascular risk, the expression of this cytokine in different cells involved in the atheroma and the increased circulating concentration observed in these patients reinforce the hypothesis. In this manuscript, the clinical, the analytical and the cellular fields are studied in order to offer a wide perspective over the subject.
\end{abstract}

Keywords: Metabolic syndrome; Osteoprotegerin; Biomarker

\section{Metabolic Syndrome - Definition and Pathophysiology}

The metabolic syndrome (MS) is a cluster of cardiometabolic alterations that include the presence of arterial hypertension, insulin resistance, dyslipemia and abdominal obesity [1]. Several organizations have proposed different definitions and the definition by the National Cholesterol Education Program's Adult Treatment Panel III has emerged as the most widely used [2]. Nowadays, the prevalence of the MS is dramatically increasing with the substantial progression of obesity and DM [3] and this is the reason why this syndrome has received more attention lately.

Prospective observational studies generally show that individuals who meet the clinical criteria for MS are at increased risk of cardiovascular events and type 2 diabetes mellitus compared to individuals without the syndrome [4]. In addition, several published meta-analysis concluded that the MS nearly doubled the risk of CV events including stroke, cardiovascular disease, myocardial infarction and cardiovascular mortality $[5,6]$. It also associated with a 1.5 fold increase in risk of all-cause mortality $[7,8]$.

The pathogenesis of the MS is complex and not clearly understood. Abnormal body fat distribution and insulin resistance have been pointed out as the main key factors implicated. Many different mechanisms are implicated in the process such as hyperinsulinemia, inflammation and coagulation alteration among others [9]. However, all these mechanisms cannot fully explain the increased cardiovascular risk observed in patients with the MS. Thus, extensive research is currently being performed evaluating other possible mechanisms. Osteoprotegerin (OPG) has emerged as a possible mechanism linking the MS and cardiovascular risk.

\section{Osteoprotegerin (OPG)}

OPG is a cytokine of the tumor necrosis factor (TNF) receptor superfamily that was first identified in $1997[10,11]$. OPG was initially described as an anti-resorptive cytokine by binding principally to receptor activator of nuclear factor (NF)-КB ligand (RANKL). OPG is part of the OPG/RANKL/receptor activator of NF-KB (RANK) pathway. Classically, this network is involved in bone remodelling, regulates the differentiation and activation of osteoclasts and hence the critical balance between bone formation and bone resorption. Initially, OPG acts as a soluble decoy receptor, negatively regulating the interaction between RANK and RANKL $[12,13]$. Although OPG was first described in bone remodelling, nowadays, there is emerging evidence of the role of OPG in the pathogenesis of atherosclerosis, calcification and cardiovascular disease [14-17].

\section{Patho-physiological role of OPG in metabolic syndrome}

To date, different data both from animal models (high-fat diet fed C57BL6 mice) [18] as well as from humans [19-21] show the relationship between OPG and MS. Furthermore, higher OPG levels are associated with risk of MS. Even, after adjusting for age, gender, ethnicity, glucose and microvascular complications, OPG remained an independent predictor of MS [21].

In these studies, OPG circulating concentration is shown to be increased in MS patients as compared to controls. Besides, OPG is expressed in adipose tissue and this expression is upregulated in patients suffering from the MS [19]. These findings highlight the positive relationship between OPG and the MS drawing attention to adipose tissue and proinflammatory changes associated with the metabolic abnormalities. OPG, increased in MS patients may trigger adipose tissue proinflammatory changes in MS and high fat diet induced obesity.

The fact that OPG is expressed in adipose tissue and that its expression is upregulated in MS patients opens up the possibility that patients with increased circulating OPG may benefit from a dietary intervention combined with exercise focused on reducing fat. Further investigation is required to confirm the usefulness of OPG as a potential target of future therapies in the cardiovascular field. Furthermore, different common treatments in these patients have 
shown to have an effect on OPG levels [22]. In this regard, selection of the therapy may be based on the modulation of OPG levels in order to implement the effects.

On the other hand, OPG positively associates with intima media thickness, coronary arterial calcium and cardiovascular risk factors [22]. Patients with elevated OPG circulating levels exhibit increased intima media thickness, presence of plaques or coronary arterial calcium [19]. OPG may add incremental information in addition to traditional risk factors and in combination with other cardiovascular risk markers. However, more studies in larger cohorts are needed to fully confirm the usefulness of OPG as a cardiovascular marker in atherosclerotic burden in MS patients.

Furthermore, the in vitro mechanism by which OPG is involved in the atherogenic and calcification process would be also worth exploring due to the relationship between MS and increased cardiovascular risk. In addition, OPG has been suggested to play a role in atherosclerosis being expressed by different cells involved in the atherogenic process. OPG seems to participate in vascular physiology and pathology in unique ways to promote endothelial cell survival, angiogenesis, monocyte or endothelial cell recruitment, and smooth muscle cell osteogenesis and calcification [23].

This molecule mediates different processes in cells known to be implicated in the atherogenic process such as endothelial cells or smooth muscle cells among others. OPG stimulates expression of several adhesion molecules as well as monocyte binding to endothelial cells [24]. Moreover, a proinflamatory milieu that characterizes MS, leads to secretion of OPG by endothelial cells [25]. When exposed to stimuli known to be upregulated in the MS, endothelial cells express and release OPG. OPG expression is increased under hyperglycemia and hyperinsulinemia and its release upregulated by inflammatory stimuli (OPG is expressed on endothelial cells and modulated by IL-1 $\beta$, insulin, and glucose, by Pérez de Ciriza et al.

Besides, in vascular smooth muscle cells, recombinant OPG promotes proliferation [26]. This evidence suggests that OPG may be released from damaged endothelial cells in response to the proinflamatory state that characterizes MS. The finding that OPG promotes the release of proinflammatory molecules on endothelial cells, suggests that OPG is not only a marker but also a mediator in atherogenesis. More studies need to be carried out to clarify the link between elevated OPG and the clinical consequences in patients with the MS.

The discovery of the expression and regulation of OPG in these cells as well as in adipose tissue may have a tremendous impact for the control of the disease. These findings will lead to a potential therapeutic target in patients with increased OPG, to reduce the deleterious effects observed in these patients.

\section{OPG as a potential biomarker}

The enthusiasm raised by OPG as a potential biomarker in metabolic syndrome patients is hampered when looking at the different published studies in detail. Interpretation and comparison of the results from different studies is complicated due to the different samples, ELISA kits and the lack of an international standard that lead to wide differences in OPG levels across studies [27,28].

Several studies [29-31] focused on establishing the adequate preanalytical and analytical conditions necessary to improve OPG measurement. In order to implement OPG determination in the clinical laboratory setting, it is vital to better control all the possible sources of variability and to allow comparison among studies.

Differences in concentration between serum and plasma (EDTA, heparin and citrate) specimens were reported. Serum samples yield lower OPG concentration when compared to plasma [29]. As a result, each laboratory should determine its own reference values and the specimen for collection due to the differences observed. Furthermore, comparison of results obtained in different specimens should be avoided.

The potential sources of circulating OPG as well as the preanalytical and analytical factors in OPG measurement studied [29] set a stone to the future development and implementation of OPG determination in clinical practice. This knowledge will allow the transfer from the research laboratory towards the clinical setting and the implementation of OPG use as a cardiovascular biomarker.

Taken all these data together, determination of OPG in MS shows promising in helping the clinician better stratify the patients at higher risk of cardiovascular disease in combination with other traditional markers. However, further studies are necessary in order to better clarify and understand the role of OPG in MS patients as well as its potential implication as a therapeutic target.

\section{References}

1. Fuentes E, Fuentes F, Vilahur G, Badimon L, Palomo I (2013) Mechanisms of chronic state of inflammation as mediators that link obese adipose tissue and metabolic syndrome. Mediators Inflamm 2013:136584.

2. National Cholesterol Education Program (NCEP) Expert panel on detection, evaluation, and treatment of high blood cholesterol in adults (Adult Treatment Panel III) (2002) Third Report of the National Cholesterol Education Program-final report. Circulation 106: 3143-3421.

3. Thaman RG, Arora GP (2013) Metabolic syndrome. Definition and pathophysiology-the discussion goes on. J Phys Pharm Adv 3: 48-56.

4. Galassi A, Reynolds K, He J (2006) Metabolic syndrome and risk of cardiovascular disease: a meta-analysis. Am J Med 119: 812-819.

5. Mottillo S, Filion KB, Genest J, Joseph L, Pilote L, et al. (2010) The metabolic syndrome and cardiovascular risk a systematic review and meta-analysis. J Am Coll Cardiol 56: 1113-1132.

6. Gami AS, Witt BJ, Howard DE, Erwin PJ, Gami LA, et al. (2007) Metabolic syndrome and risk of incident cardiovascular events and death: a systematic review and meta-analysis of longitudinal studies. J Am Coll Cardiol 49: 403-414.

7. Hu G, Qiao Q, Tuomilehto J, Balkau B, Borch-Johnsen K, et al. (2004) Prevalence of the metabolic syndrome and its relation to all-cause and cardiovascular mortality in nondiabetic European men and women. Arch Intern Med 164: 1066-1076.

8. Wu SH, Liu Z, Ho SC (2010) Metabolic syndrome and all-cause mortality: a meta-analysis of prospective cohort studies. Eur J Epidemiol 25: 375-384.

9. Alberti KG, Zimmet P, Shaw J (2006) Metabolic syndrome-a new worldwide definition. A Consensus Statement from the International Diabetes Federation. Diabet Med 23: 469-480.

10. Simonet WS, Lacey DL, Dunstan CR, Kelley M, Chang MS, et al. (1997) Osteoprotegerin: A novel secreted protein involved in the regulation of bone density. Cell 89: 309-319.

11. Tsuda E, Goto M, Mochizuki S, Yano K, Kobayashi F, et al. (1997) Isolation of a novel cytokine from human fibroblasts that specifically inhibits osteoclastogenesis. Biochem Biophys Res Commun 234: 137-142.

12. Van Campenhout A, Golledge J (2009) Osteoprotegerin, vascular calcification and atherosclerosis. Atherosclerosis 204: 321-329. 
Citation: Villacampa CPC (2016) Osteoprotegerin: A Promising Biomarker in the Metabolic Syndrome - New Perspectives. Biochem Anal Biochem 5: 289. doi:10.4172/2161-1009.1000289

Page 3 of 3

13. Venuraju SM, Yerramasu A, Corder R, Lahiri A (2010) Osteoprotegerin as a predictor of coronary artery disease and cardiovascular mortality and morbidity. J Am Coll Cardiol 55: 2049-2061.

14. Vik A, Mathiesen EB, Brox J, Wilsgaard T, Njolstad I, et al. (2011) Serum osteoprotegerin is a predictor for incident cardiovascular disease and mortality in a general population: The Tromso Study. J Thromb Haemost 9: 638-644.

15. Semb AG, Ueland T, Aukrust P, Wareham NJ, Luben R, et al. (2009) Osteoprotegerin and soluble receptor activator of nuclear factor-kappaB ligand and risk for coronary events: a nested case-control approach in the prospective EPIC-Norfolk population study 1993-2003. Arterioscler Thromb Vasc Biol 29: 975-980.

16. Mogelvang R, Pedersen SH, Flyvbjerg A, Bjerre M, Iversen AZ, et al. (2012) Comparison of osteoprotegerin to traditional atherosclerotic risk factors and high-sensitivity C-reactive protein for diagnosis of atherosclerosis. Am J Cardiol 109: 515-520.

17. Hosbond SE, Poulsen TS, Diederichsen AC, Nybo M, Rasmussen LM, et al. (2012) Osteoprotegerin as a marker of atherosclerosis: a systematic update. Scand Cardiovasc J 46: 203-211.

18. Bernardi S, Fabris B, Thomas M, Toffoli B, Tikellis C, et al. (2014) Osteoprotegerin increases in metabolic syndrome and promotes adipose tissue proinflammatory changes. Mol Cell Endocrinol 394: 13-20.

19. Perez de Ciriza C, Moreno M, Restituto P, Bastarrika G, Simon I, et al. Circulating osteoprotegerin is increased in the metabolic syndrome and associates with subclinical atherosclerosis and coronary arterial calcification. Clin Biochem 47: 272-278.

20. Akinci B, Celtik A, Yuksel F, Genc S, Yener S, et al. (2011) Increased osteoprotegerin levels in women with previous gestational diabetes developing metabolic syndrome. Diabetes Res Clin Pract 91: 26-31.

21. Tavintharan S, Pek LT, Liu JJ, Ng XW, Yeoh LY, et al. (2014) Osteoprotegerin is independently associated with metabolic syndrome and microvascular complications in type 2 diabetes mellitus. Diab Vasc Dis Res 11: 359-362.

22. Perez de Ciriza C, Lawrie A, Varo N (2015) Osteoprotegerin in Cardiometabolic Disorders. Int J Endocrinol 2015: 564934
23. Collin-Osdoby P, Rothe L, Anderson F, Nelson M, Maloney W, et al. (2001) Receptor activator of NF-kappa B and osteoprotegerin expression by human microvascular endothelial cells, regulation by inflammatory cytokines, and role in human osteoclastogenesis. J Biol Chem 276: 20659-20672.

24. Mangan SH, Van Campenhout A, Rush C, Golledge J (2007) Osteoprotegerin upregulates endothelial cell adhesion molecule response to tumor necrosis factor-alpha associated with induction of angiopoietin-2. Cardiovasc Res 76: 494-505.

25. Zannettino AC, Holding CA, Diamond P, Atkins GJ, Kostakis P, et al. (2005) Osteoprotegerin (OPG) is localized to the Weibel-Palade bodies of human vascular endothelial cells and is physically associated with von Willebrand factor. J Cell Physiol 204: 714-723.

26. Lawrie A, Waterman E, Southwood M, Evans D, Suntharalingam J, et al. (2008) Evidence of a role for osteoprotegerin in the pathogenesis of pulmonary arterial hypertension. Am J Pathol 172: 256-264.

27. Clancy P, Oliver L, Jayalath R, Buttner P, Golledge J (2006) Assessment of a serum assay for quantification of abdominal aortic calcification. Arterioscler Thromb Vasc Biol 26: 2574-2576.

28. Naylor KE, Rogers A, Fraser RB, Hall V, Eastell R, et al. (2003) Serum osteoprotegerin as a determinant of bone metabolism in a longitudinal study of human pregnancy and lactation. J Clin Endocrinol Metab 88: 5361-5365.

29. Perez de Ciriza C, Lawrie A, Varo N (2014) Influence of pre-analytical and analytical factors on osteoprotegerin measurements. Clin Biochem 47: $1279-1285$

30. Chan BY, Buckley KA, Durham BH, Gallagher JA, Fraser WD (2003) Effect of anticoagulants and storage temperature on the stability of receptor activator for nuclear factor-kappa B ligand and osteoprotegerin in plasma and serum. Clin Chem 49: 2083-2085.

31. Sennels HP, Jacobsen S, Jensen T, Hansen MS, Ostergaard M, et al. (2007) Biological variation and reference intervals for circulating osteopontin, osteoprotegerin, total soluble receptor activator of nuclear factor kappa B ligand and high-sensitivity C-reactive protein. Scand J Clin Lab Invest 67: 821-835 